\title{
Examining Evidence for Conventional versus Complementary Therapies to Address Chronic Obstructive Pulmonary Disease
}

\author{
Jared G Kerr*, Susan M Sinclair*, Robert W Boyce, Harold Campbell, David J Giordano and Justine J Reë ${ }^{\star}$
}

College of Health and Human Services, University of North Carolina, Wilmington, USA

*Corresponding author: Justine J Reel, PhD, LPC, CC-AASP, College of Health and Human Services, University of North Carolina, Wilmington, USA, Tel: 910962-7341; E-mail:reelj@uncw.edu

Received date: April 23, 2016; Accessed date: April 27, 2016; Published date: April 29, 2016

Copyright: @ 2016 Kerr JG, et al. This is an open-access article distributed under the terms of the Creative Commons Attribution License, which permits unrestricted use, distribution, and reproduction in any medium, provided the original author and source are credited.

\begin{abstract}
Chronic obstructive pulmonary disease (COPD) is the third leading cause of death in the United States. COPD is a complex disease for which the cause and cure remain elusive. Conventional treatments for COPD have traditionally included medications and surgery. However, these conventional therapies have limitations and have been insufficient to reliably cease disease progression or improve the patient's quality of life in a meaningful way. Complementary therapies, such as yoga, mindfulness, and tai chi, have emerged that may show promising innovations for improving COPD patient care; however, there is a paucity of studies to demonstrate clinical efficacy. Initial research on complementary therapies has revealed hope that these innovative approaches may help alleviate symptoms, improve quality of life, and reduce depression and anxiety in people with COPD. While there is a growing body of research surrounding complementary therapies for COPD, the weight of the evidence remains limited.
\end{abstract}

Keywords: Chronic obstructive pulmonary function; COPD therapies; Complementary therapies; Adjunct therapies

\section{Introduction}

Chronic Obstructive Pulmonary Disease (COPD) is currently the third leading cause of death in the United States [1] with mortality rates expected to rise to become the third leading cause of death worldwide by 2030 [2-6]. COPD is characterized by having a persistent airflow limitation that is usually progressive and associated with an enhanced chronic inflammatory response in the airways and the lung to noxious particles or gases [5]. Periodic exacerbations (i.e., a worsening or flare-up) increase the rate of decline in lung function beginning with the second exacerbation, and the rate of decline increases with each severe exacerbation (i.e., requiring hospitalization) thereafter [6].

Death from COPD is more likely to occur in the weeks immediately following a severe exacerbation [6]. Therefore, delaying the second severe exacerbation and intensifying in-patient treatment of COPD exacerbations to prevent early mortality are two important strategies for COPD management [6]. The purpose of this paper is to contrast the evidence for conventional therapies such as medications and surgery used to treat COPD with promising complementary therapies. Specifically, this paper will demonstrate that conventional therapies have received more attention in the literature than complementary therapeutic approaches. Thus, more clinical studies are needed to support the further development and use of these innovative treatment approaches.

\section{Conventional Therapies}

Conventional therapies for COPD typically include medications, surgery, and pulmonary rehabilitation (i.e., a program of exercise training, education, and psychosocial support). The goals of conventional therapies are to manage COPD symptoms and mitigate exacerbations [5-9].

\section{Medications}

Medications for COPD include bronchodilators, corticosteroids, phosphodiesterase- 4 inhibitors, and theophylline. Medications are prescribed in the early stages of COPD and increase in number and complexity as the disease progresses. Although medications are an important aspect of COPD management; they have not been shown conclusively to modify the long-term decline in lung function [5]. In addition, both serious and non-serious side effects are associated with COPD medications, including dry mouth, headache, tremor, increased heart rate, and nausea [10]; and an increased risk for cardiac arrhythmias [11], fatal and non-fatal cardiovascular events and pneumonia [12-14].

\section{Surgery}

Surgery is reserved for select patients with severe disease, poor quality of life related to breathing difficulties, and inadequate response to medications. For many, surgery is not an option due to the potential for complications associated with general anesthesia, particularly cardiovascular instability and post-operative pulmonary complications [15]. Bullectomy and lung volume reduction surgery are surgical options in which damaged lung tissue is removed, allowing the remaining lung tissue to function more effectively. Lung transplantation is less frequently used due to the risk for serious postoperative complications such as acute rejection and opportunistic infections [16].

\section{Pulmonary Rehabilitation}

Pulmonary rehabilitation is a program of exercise training, ongoing education, nutritional intervention, and psychosocial support [17]. Pulmonary rehabilitation is generally prescribed for people with severe 
Page 2 of 4

COPD that has resulted in disability and loss of function [18]. Outcomes from this therapy include relieving breathing difficulties, lessening fatigue, improving emotional function, and enhancing an individual's sense of control over their COPD [19]. These in-patient and out-patient programs vary in content, frequency, and other attributes. Home-based programs have been shown to be an effective alternative with both short- and long-term benefits [20]. Pulmonary rehabilitation is included in treatment guidelines, but with considerably less detail and attention than medications [7-9]. The American College of Sports Medicine (ACSM) is one leading organization that has developed exercise guidelines for COPD [20-22]. They support light to moderate exercise training, which can reduce the associated disability of COPD by improving endurance, strength, and breathing efficiency.

\section{Complementary Therapies}

A diverse range of complementary therapies have been used to manage COPD. Complementary therapies are viewed as "nonmainstream" therapies used alongside conventional therapy [20]. Examples of these therapeutic approaches include yoga, tai chi, geroprotectors (i.e., agents that target cellular aging), innovative devices, and herbal products. Other complementary therapies that are currently used to manage COPD include anti-oxidants, nutritional supplements, mindfulness, mind/body medicine, and acupuncture. Unfortunately, these therapies are typically not covered by health insurance and may be under-utilized by healthcare providers. Therefore, clinical studies are needed to provide evidence for treatment efficacy related to these promising adjunct therapies.

\section{Yoga and Tai Chi}

Studies of yoga training programs involving postures and controlled exhalations have shown significant improvements in pulmonary function and exercise capacity among people with COPD [23-25]. Tai chi and mindful breathing may improve quality of life and exercise capacity [26].

\section{Antioxidants and Geroprotectors}

The inhalation of tobacco smoke and other toxins disrupt the balance of oxidants and antioxidants in the lung tissue. This imbalance results in increased levels of harmful reactive oxygen species and subsequent lung damage. Accordingly, dietary antioxidants and antioxidant supplements have been evaluated as a useful therapeutic approach for managing stable COPD [27-29]. Several clinical studies have been conducted, with mixed results [27,29]. In addition, information on the pharmacokinetics, bioavailability, toxicity, and absorption of various exogenous antioxidants and activators of endogenous antioxidants is lacking [27].

Geroprotector therapy has shown promise in slowing the progression of COPD [30]. Recent research suggests that genotoxic stress from toxins found in cigarette smoke is associated with accelerated aging and functional alterations of the airway epithelial cells, potentially contributing to the onset of COPD [31-33]. Geroprotector therapy seeks to slow this aging process by reducing oxidative stress through fasting, supplemental melatonin, resveratrol (grapes, peanuts, red wine) and Nrf2 activators (broccoli).

\section{Devices}

Devices based on airway clearance techniques are used to facilitate removal of mucus from the lungs, which lowers resistance in the airways and improves the ease of breathing. There are four major types of devices; three require the individual to exhale into the device and one works externally on the chest wall. These innovative devices apply air pressure, vibration, or acoustic impedance to the large and small airways to loosen the mucus making it easier to remove through coughing and huffing. Positive expiratory pressure (PEP) therapy uses a face-mask or mouthpiece with a one-way valve to create air pressure in the upper and lower airways. Oscillating PEP (oPEP) devices use PEP therapy with high-frequency oscillations to create a controlled vibration in the airways $[34,35]$. Acoustic impedance devices use sound waves to create low-frequency vibrations in the airways [36]. And finally, an inflatable vest is used to transfer high frequency vibration to the chest wall [37].

\section{Herbal Products}

Systematic reviews and meta-analyses have shown encouraging results in studies of herbal products, including traditional Chinese medicine, for COPD [38-40]. Among the studies reviewed, significant improvements in health-related quality of life, exercise endurance, symptoms, exacerbations, and lung function have been reported. However, interpretation of these findings is difficult based on weak research methodologies, in general. In addition, the potential for adverse events associated with these products, and their use in combination with other therapies, especially medications, has not been thoroughly addressed.

\section{Literature Search}

To evaluate the volume of scientific literature related to conventional and complementary therapies for COPD, a literature search was conducted using a custom database, which includes: Aquatic Science \& Fisheries Abstracts (ASFA) 3: Aquatic Pollution \& Environmental Quality; ebrary e-books; Physical Education Index; PILOTS: Published International Literature On Traumatic Stress; Pharmaceutical News Index; ProQuest Career and Technical Education; ProQuest Family Health; ProQuest Health \& Medical Complete; ProQuest Health Management; ProQuest Nursing \& Allied Health Source; ProQuest Social Science Journals; ProQuest Environmental Science Collection.

A free text search was conducted for "pulmonary disease, chronic obstructive" and the following keyword(s): acupuncture, antioxidant ${ }^{*}$, device, geroprotectors, herb ${ }^{*}$, inhaler, Lung Flute, medication, meditation, mind body, mindfulness, nutritional supplement ${ }^{*}$, pulmonary rehabilitation, rocking bed, surgical treatment, tai chi, traditional Chinese medicine, yoga. Wildcards were used for word variations. Non-therapeutic devices were excluded. Results were limited to full text, peer reviewed, scholarly journals, published after the year 2000, and English language.

\section{Results from Literature Search}

Several complementary therapies have been used to treat COPD; however, these therapies have been largely absent from the treatment guidelines followed by the medical community. Therefore, randomized clinical studies are sorely needed for complementary therapies to expand the evidence-based treatment options for COPD. 
The results, which are summarized in Table 1, illustrate a disproportionate number of publications that cover conventional therapy $(83 \%)$. The majority of these COPD studies discuss medications $(39 \%)$ or pulmonary rehabilitation $(33 \%)$ as the primary treatment modality. Complementary therapies account for only $17 \%$ the publications identified (Table 1).

\begin{tabular}{|l|l|l|}
\hline Therapy Category & Group & $\mathbf{n}(\%)$ \\
\hline Conventional Therapy & Medications & $779(39 \%)$ \\
\hline & Pulmonary Rehabilitation & $662(33 \%)$ \\
\hline Subtotal & Surgical Treatments & $204(10 \%)$ \\
\hline Complementary Therapy & Devices & $1645(83 \%)$ \\
\hline & Herbal & $171(9 \%)$ \\
\hline & Antioxidants & $57(3 \%)$ \\
\hline & Supplements & $35(2 \%)$ \\
\hline & Traditional Chinese Medicine & $22(1 \%)$ \\
\hline Subtotal & Mind-Body & $18(<1 \%)$ \\
\hline Total & & $336(17 \%)$ \\
\hline
\end{tabular}

Table 1: Summary of literature search results for COPD therapies by therapy category and keyword search grouping.

\section{Future Directions and Conclusion}

COPD is a complex disease for which the cause and cure remain elusive. Conventional therapies are inadequate for halting disease progression or improving quality of life [2]. Another concern associated with conventional therapies is the potential for serious adverse events (e.g. an increased risk for cardiac arrhythmias [11], fatal and non-fatal cardiovascular events [12,13], and pneumonia [13]). Current treatment guidelines for COPD focus on medications as the primary treatment modality, although the non-pharmacologic option of pulmonary rehabilitation (which includes exercise training) is included. However, procedural descriptions concerning pulmonary rehabilitation are lacking [7-9].

Research on patient-centered therapies is beginning to reveal models that alleviate symptoms and improve quality of life through mindfulness, yoga, nutrition, and the treatment of anxiety [3] as an adjunct to medications. While there is a growing body of research surrounding complementary therapies for COPD, the weight of the evidence remains limited.

\section{References}

1. Cox LA (2011) A causal model of chronic obstructive pulmonary disease (COPD) risk. Risk Analysis 31: 38-62.

2. Conti V, Corbi G, Manzo V, Pelaia G, Filippelli A, et al. (2015) Sirtuin 1 and aging theory for chronic obstructive pulmonary disease. Anal Cell Pathol (Amst) 2015: 897327.

3. Chen Q, Wu C, Gao Y, Chen L, Liu Y (2015) A clinical study on the role of psychosomatic therapy in evaluation and treatment of patients with chronic obstructive pulmonary disease complicated with anxietydepression disorder. Int J Clin Exp Med 28: 16613-16619.

4. (2001) World Health Organization. Chronic respiratory diseases. Chronic obstructive pulmonary disease.

5. Global Initiative for Chronic Obstructive Lung Disease (GOLD) (2016) Global strategy for the diagnosis management and prevention of chronic obstructive pulmonary disease.

6. Suissa S, Dell'Aniello S, Ernst P (2012) Long-term natural history of chronic obstructive pulmonary disease: severe exacerbations and mortality. Thorax 67: 957-963.

7. Qaseem A, Wilt TJ, Weinberger SE, Hanania NA, Criner G, et al. (2011) Diagnosis and management of stable chronic obstructive pulmonary disease: a clinical practice guideline update from the American College of Physicians, American College of Chest Physicians, American Thoracic Society, and European Respiratory Society. Ann Intern Med 155: 179-191.

8. National Institute for Health and Care Excellence (NICE) (2010) Chronic obstructive pulmonary disease in over 16s: diagnosis and management. Clinical guideline.

9. Abramson M, Frith P, Yang I, McDonald C, Hancock K, et al. (2016) COPD-X Concise Guide for Primary Care. Brisbane. Lung Foundation Australia.

10. Grimes GC, Manning JL, Patel P, Via RM (2007) Medications for COPD: a review of effectiveness. Am Fam Physician 76: 1141-1148.

11. Wilchesky M, Ernst P, Brophy JM, Platt RW, Suissa S (2012) Bronchodilator use and the risk of arrhythmia in COPD: part 1: Saskatchewan cohort study. Chest 142: 298-304.

12. Gershon A, Croxford R, Calzavara A, To T, Stanbrook MB, et al. (2013) Cardiovascular safety of inhaled long-acting bronchodilators in individuals with chronic obstructive pulmonary disease. JAMA Intern Med 173: 1175-1185.

13. Decramer ML, Hanania NA, Lötvall JO, Yawn BP (2013) The safety of long-acting $\beta 2$-agonists in the treatment of stable chronic obstructive pulmonary disease. Int J Chron Obstruct Pulmon Dis 8: 53-64.

14. Tricco AC, Strifler L, Veroniki AA, Yazdi F, Khan PA, et al. (2015) Comparative safety and effectiveness of long-acting inhaled agents for treating chronic obstructive pulmonary disease: A systematic review and network meta-analysis. BMJ Open 5.

15. Lumb A, Biercamp C (2014) Chronic obstructive pulmonary disease and anesthesia. BJA Education 14: 1-5.

16. Aziz F, Penupolu S, Xu X, He J (2010) Lung transplant in end-staged chronic obstructive pulmonary disease (COPD) patients: A concise review. J Thorac Dis 2: 111-116.

17. Spruit MA, Pitta F, Garvey C, ZuWallack RL, Roberts, et al. (2014) Differences in content and organizational aspects of pulmonary rehabilitation programmes. Eur Respir J 43: 1326-1337.

18. Hill NS (2006) Pulmonary Rehabilitation. Proc Am Thorac Soc 3: 66-74.

19. McCarthy B, Casey D, Devane D, Murphy K, Murphy E, et al. (2015) Pulmonary rehabilitation for chronic obstructive pulmonary disease. Cochrane Database Syst Rev 2: CD003793.

20. Grosbois JM, Gicquello A, Langlois C, Le Rouzic O, Bart F, et al. (2015) Long-term evaluation of home-based pulmonary rehabilitation in patients with COPD. Int J Chron Obstruct Pulmon Dis 10: 2037-2044.

21. American College of Sports Medicine (2016) ACSM Current Comment. Indianapolis: American College of Sports Medicine.

22. (2008) National Institutes of Health. National Center for Complementary and Integrative Health. Complementary, Alternative, or Integrative Health: What's In a Name?

23. Liu XC, Pan L, Hu Q, Dong WP, Yan JH, et al. (2014) Effects of yoga training in patients with chronic obstructive pulmonary disease: a systematic review and meta-analysis. J Thorac Dis 6: 795-802.

24. Fulambarker A, Farooki B, Kheir F, Copur AS, Srinivasan L, et al. (2012) Effect of yoga in chronic obstructive pulmonary disease. Am J Ther 2: 96-100.

25. Donesky-Cuenco D, Nguyen HQ, Paul S, Carrieri-Kohlman V (2009) Yoga therapy decreases dyspnea-related distress and improves functional 
Citation: Kerr JG, Sinclair SM, Boyce RW, Campbell H, Giordano DJ, et al. (2016) Examining Evidence for Conventional versus Complementary Therapies to Address Chronic Obstructive Pulmonary Disease. J Gen Practice 4: 247. doi:10.4172/2329-9126.1000247

Page 4 of 4

performance in people with chronic obstructive pulmonary disease: A pilot study. J Altern Complement Med 15: 225-234.

26. Yeh GY, Wayne PM, Litrownik D, Roberts DH, Davis RB, et al. (2014) Ta chi mind-body exercise in patients with COPD: study protocol for a randomized controlled trial. Trials 15: 337

27. Rahman I, MacNee W (2012) Antioxidant pharmacological therapies for COPD. Curr Opin Pharmacol 3: 256-265.

28. Domej W, Oettl K, Renner W (2014) Oxidative stress and free radicals in COPD - implications and relevance for treatment. International Journal of Chronic Obstructive Pulmonary Disease 9: 1207-1224.

29. Tsiligianni IG, van der Molen T (2010) A systematic review of the role of vitamin insufficiencies and supplementation in COPD. Respir Res 11: 171.

30. Ito K, Colley T, Mercado N (2012) Geroprotectors as a novel therapeutic strategy for COPD, an accelerating aging disease. Int J Chron Obstruct Pulmon Dis 7: 641-652.

31. Tsuji T, Aoshiba K, Nagai A (2010) Alveolar cell senescence exacerbates pulmonary inflammation in patients with chronic obstructive pulmonary disease. Respiration 80: 59-70

32. Zhou F, Onizawa S, Nagai A, Aoshiba K (2011) Epithelial cell senescence impairs repair process and exacerbates inflammation after airway injury. Respir Res 12: 78 .

33. Geraghty P, Hardigan A, Foronjy RF (2014) Cigarette Smoke Activates the Proto-Oncogene c-Src to Promote Airway Inflammation and Lung Tissue Destruction. Am J Respir Cell Mol Biol 50: 559-570.
34. Morrison L, Agnew J (2014) Oscillating devices for airway clearance in people with cystic fibrosis. Cochrane Database Syst Rev 7: CD006842.

35. Svenningsen S, Paulin GA, Sheikh K, Guo F, Hasany A, et al. (2016) Oscillatory positive expiratory pressure in chronic obstructive pulmonary disease. COPD 1: 66-74.

36. Sethi S, Yin J, Anderson PK (2014) Lung flute improves symptoms and health status in COPD with chronic bronchitis: A 26 week randomized controlled trial. Clin Transl Med 3: 29.

37. Mahajan AK, Diette GB, Hatipoglu U, Bilderback A, Ridge A, et al. (2011) High frequency chest wall oscillation for asthma and chronic obstructive pulmonary disease exacerbations: a randomized sham-controlled clinical trial. Respir Res 12: 120.

38. Guo R, Pittler MH, Ernst E (2006) Herbal medicines for the treatment of COPD: a systematic review. Eur Respir J 2: 330-338.

39. An X, Zhang AL, May BH, Lin L, Xu Y, et al. (2012) Oral Chinese herbal medicine for improvement of quality of life in patients with stable chronic obstructive pulmonary disease: a systematic review. J Altern Complement Med 8: 731-743.

40. Haifeng W, Hailong Z, Jiansheng L, Xueqing Y, Suyun L, et al. (2015) Effectiveness and safety of traditional Chinese medicine on stable chronic obstructive pulmonary disease: A systematic review and meta-analysis. Complement Ther Med 4: 603-611. 